\title{
A combination of COVID-19 and dengue fever in Bangladesh: Preparedness of Bangladesh
}

\author{
Promit Barua Chowdhury $^{1 *}$, Sorif Hossain ${ }^{\text {* }}$, Raaj Kishore Biswas ${ }^{2 *}$
}

\footnotetext{
${ }^{1}$ Institute of Statistical Research and Training, University of Dhaka, Bangladesh

${ }^{2}$ Transport and Road Safety (TARS) Research Centre, School of Aviation, University of New South Wales, Australia

*Joint first authorship.
}

\section{The existing COVID-19 crisis would worsen if dengue out- break occurs in monsoon (June- September) following the same pattern of last year (2019).} a countrywide lockdown from 26 March, which was periodically extended up to 30 May, following a surge in infections on 13 May and since then the most vulnerable areas are under experimental lockdown. Restrictions are strictly imposed on transportation except for emergency vehicles. A fund of 12.5 million BDT is allocated for the poor and badly affected due to the outbreak [3].

A shortage of testing kits and other medical facilities were observed in Bangladesh since the early onset of the COVID-19 outbreak, despite continuous insistence on 'well-prepared health system' by the authorities [4]. As a result, only 11223 tests were conducted on the first 5 weeks, which was the lowest worldwide testing rate [2]. Even the treatments for COVID-19 were delayed due to inadequate protective equipment in the health facilities. As a result, high infection rate among health workers were observed along with 35 reported cases of deaths of doctors [5]. Many health care workers refused to provide services, which lead to an increased fear and anxiety in the community. However, at the end of April the number of resources were increased, with currently 60 test centers alongside a stock of 1392601 personal protect equipment, 13284 isolation beds, 3135420 masks, 562439 gloves, and 179759 hand sanitizers [6].

Besides the ongoing pandemic, Bangladesh faced the onslaught of dengue last year (2019) with 2020 season expected to start in June, a viral infection caused by four types of viruses (DENV-1, DENV-2, DENV3, DENV-4) from the Flaviviridae family. These viruses are typically transmitted infected Aedes aegypti and Aedes albopictus female mosquitoes. These mosquitoes thrive in areas withstanding water, including puddles, water tanks, containers, and old tires. The lack of reliable sanitation and regular garbage collection also contribute to the spread of the mosquitoes. Dengue infection could be asymptomatic, which makes it highly transmissible. Generally, the infection is characterized by flu-like symptoms including multiple waves of sudden high fevers, which may progress to the Dengue Hemorrhagic Fever (DHF) [7]. Similar to COVID-19, symptomatic treatments are the only cure for the DHF. Despite being an irregular 
An urgent preparedness call is necessary to address the dengue outbreak if Bangladesh plans to overcome the already stretched health system.

event in the past, Bangladesh experienced its deadliest outbreak of dengue fever with 101354 reported cases and 179 deaths in 2019 [8].

The combination of dengue fever and COVID-19 (Figure 1) would aggravate the already stretched health system of Bangladesh. A multicenter early needs assessment study warned that dengue and natural disasters could worsen the COVID-19 crisis in Bangladesh [9]. The assessment study also identified key indicators of risks exposures to COVID-19 including congested urban focused unsustainable vulnerability, demographic and social vulnerability, economic and physical vulnerability, and recurrent disaster vulnerability, which listed the 20 most vulnerable districts out of total 64. The efforts of health sector are now concentrated on controlling the COVID-19 pandemic, which also needs to prepare for dengue outbreak immediately before any further escalation.

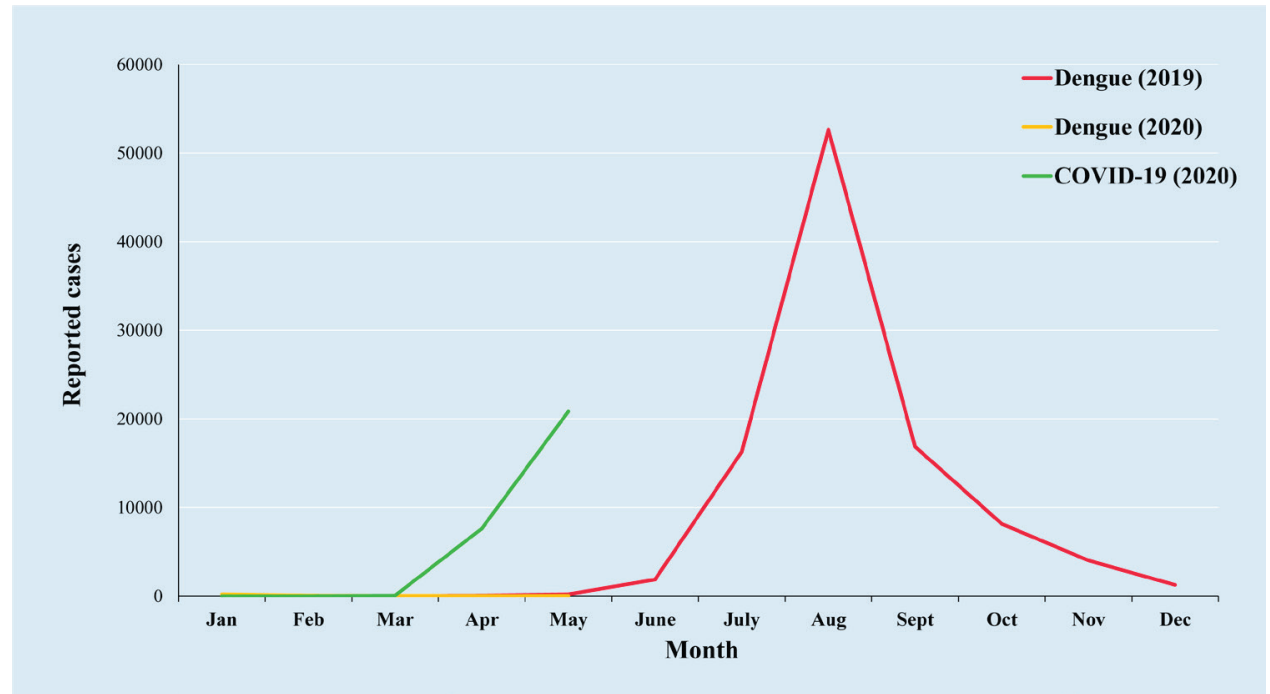

Figure 1. Dengue cases for 2019 and 2020, and COVID-19 cases up to May 21, 2020.

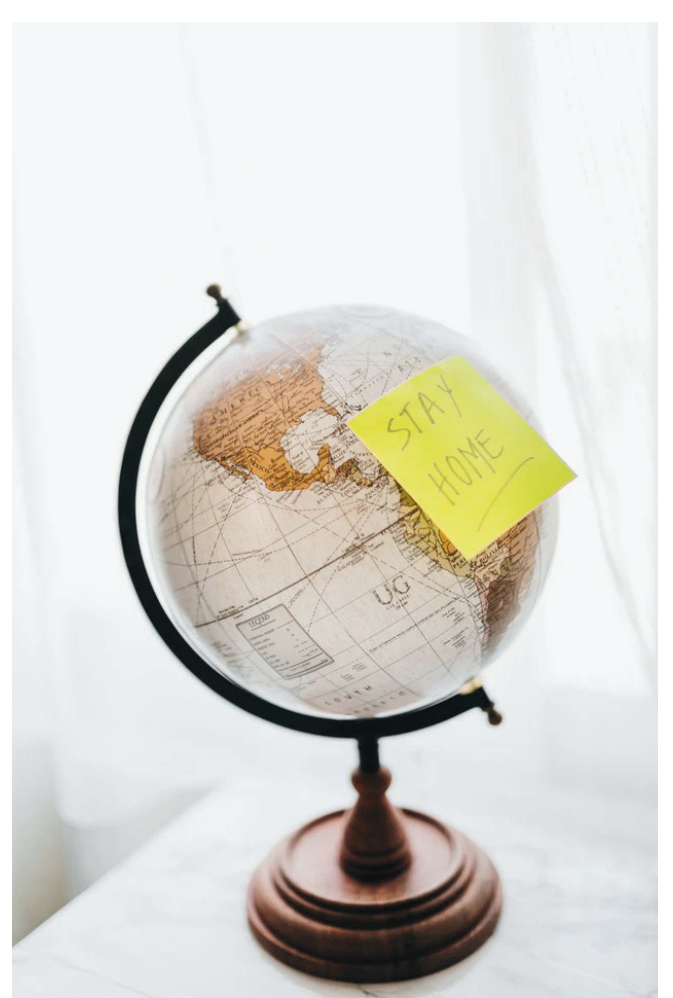

Photo: From https://unsplash.com/photos/W3IXtchd1pE.
With the onset of the monsoon season expected between the end of May to September, the density of Aedes population is predicted to rise. The construction sites are considered as the main sources of Aedes breeding as well as the currently idle terminal stations. If the dengue epidemic spreads at a similar rate of the COVID-19, it would be impossible to equip health facilities to treat patients suffering from both the COVID-19 and the DHF. In overcrowded health facilities, maintaining social distance would be challenging. Although the number of tests has increased over the last few weeks, the rate of test conducted is still 3242 tests per million (as of 16 June 2020), which is insufficient for a country with around 161.4 million population. The scenario would get worse due to the similar nature of symptoms for these two diseases. The delay of identifying the sources of flu-like symptoms, be it from dengue fever or coronavirus, would affect treatment speed as well as recovery rate.

The Local Government Rural Development (LGRD) department has allocated 3 billion BDT (US $\$ 35$ million) for cleaning and joint awareness campaigns for COVID-19 and dengue fever [10]. However, data deficiency has created multifaceted problems for the policymakers [4]. Masks, sanitizers, gloves, and PPEs (for front line workers) should be in manufactured widely and be made a part of daily lives. Evidence based policies need to in place for lockdown relaxation, which could consider slowly opening districts with low infection rates and continuous random sampling to monitor progress [11]. The rules of social distancing in business or industrial zones should be strictly maintained as well as surveilling environments that are breeding grounds for Aedes. Bangladesh need to be better prepared for dengue than it was for the COVID-19, otherwise a disaster awaits for the health sector. 
Acknowledgements: We would like to show our gratitude towards Institute of Epidemiology Disease Control and Research (IEDCR) and Directorate General of Health Services (DGHS) for creating an open-access data source for daily COVID-19 and dengue infection reports.

Funding: This research received no specific grant from any funding agency in the public, commercial, or not-forprofit sectors.

Authorship contributions: PBC conceptualized the study and draft the manuscript. SH coded the graph and reviewed the manuscript. RKB supervised and critically revised the manuscript. All authors read and approved the final manuscript.

Competing interests: The authors completed the ICMJE Unified Competing Interest form (available upon request from the corresponding author), and declare no conflicts of interest.

1 Medscape, Coronavirus Disease 2019 (COVID-19), Available: https://emedicine.medscape.com/article/2500114-overview. Accessed: 21 May 2020.

2 La France au Bangladesh - Ambassade de France à Dacca, COVID 19, Available: https://bd.ambafrance.org/Covid-19. Accessed: 16 June 2020.

3 Anadolu Agency. COVID-19: Bangladesh to extend lockdown until May 16, Available: https://www.aa.com.tr/en/asia-pacific/covid-19-bangladesh-to-extend-lockdown-until-may-16/1826659, Accessed: 21 May 2020.

4 Huq S, Biswas RK. COVID-19 in Bangladesh: Data deficiency to delayed decision. J Glob Health. 2020;10:010342. Medline:32373321 doi:10.7189/jogh.10.010342

5 The Daily Star. Why are we losing so many of our doctors? Available: https://www.thedailystar.net/editorial/news/whyare-we-losing-so-many-our-doctors-1913813. Accessed: 16 June 2020.

6 World Health Organization. Coronavirus disease (COVID-2019) Bangladesh situation reports. Available: https://www. who.int/bangladesh/emergencies/coronavirus-disease-(covid-19)-update/coronavirus-disease-(covid-2019)-bangladesh-situation-reports. Accessed: 16 June 2020.

7 International Association for Medical Assistance to Travelers. Bangladesh General Health Risks: Dengue, Available: https:// www.iamat.org/country/bangladesh/risk/dengue. Accessed: 22 May 2020.

8 The Daily star, Dengue Amid Covid-19 Outbreak: With rain comes risk Available: https://www.thedailystar.net/backpage/ news/dengue-amid-covid-19-outbreak-rain-comes-risk-1897489. Accessed: 21 May 2020.

9 Needs Assessment Working Group. COVID-19: Bangladesh Multi-Sectoral Anticipatory Impact and Needs Analysis. Available: https://www.humanitarianresponse.info/en/operations/bangladesh/document/covid-19-bangladesh-multi-sectoral-anticipatory-impact-and-needs. Accessed: 22 May 2020

10 Union of Catholic Asian News. After Covid-19, Bangladesh faces dengue threat, Available: https://www.ucanews.com/ news/after-covid-19-bangladesh-faces-dengue-threat/88059, Accessed: 21 May 2020.

11 Biswas RK, Huq S, Afiaz A. Relaxed lockdown in Bangladesh during COVID-19: Should economy outweigh health? Int J Health Policy Manag. 2020;•••:10. Online ahead of print. Medline:32610806

\section{Correspondence to:}

Promit Barua Chowdhury

Institute of Statistical Research and

Training

University of Dhaka

Bangladesh

pchowdhury@isrt.ac.bd 